\title{
Proteomic analysis of pre-diapause, diapause and post-diapause larvae of the wheat blossom midge, Sitodiplosis mosellana (Diptera: Cecidomyiidae)
}

\author{
Wei-Ning CHENG ${ }^{1}$, Xiu-Lian LI ${ }^{1}$, Feng YU ${ }^{2}$, Yi-Ping LI ${ }^{1}$, Jian-Jun LI ${ }^{1}$ and Jun-XIang WU ${ }^{1, *}$ \\ ${ }^{1}$ The College of Plant Protection, Key Laboratory of Plant Protection Resources and Pest Management, Ministry of Education, \\ Northwest A \& F University, Yangling, 712100 Shaannxi, China; e-mail: junxw@yahoo.com.cn \\ ${ }^{2}$ The College of Animal Science and Technology, Northwest A \& F University, Yangling, 712100 Shaannxi, China
}

Key words. Sitodiplosis mosellana, diapause, proteome, 2-dimensional electrophoresis, mass spectrometry

\begin{abstract}
To determine the relationship between protein expression and insect diapause, a proteomic approach was used to investigate the proteins extracted from larvae of the wheat blossom midge Sitodiplosis mosellana Gehin at different developmental stages, including pre-diapause, over-summering diapause, over-wintering diapause and post-diapause. Using 2-DE gels stained with coomassie brilliant blue, about 300 protein spots were detected in the extracts of pre-diapause larvae and 275 for those in each of the other stages. There were 91,92 and 95 protein spots that showed more than a 2 -fold change in abundance in the over-summering diapause, over-wintering diapause and post-diapause stages compared with pre-diapause. Eight protein spots, which showed the greatest difference in the larvae at different stages of diapause, were analyzed using Matrix-assisted laser desorption ionization time of flight mass spectrometry (MALDI-TOF-MS). Seven of them were successfully identified from their peptide mass fingerprints using the NCBInr database. They were proopiomelanocortin, NADH dehydrogenase subunit 1 and F10F2.5, which were up-regulated or unique to pre-diapause larvae, IKK interacting protein isoform 2 up-regulated in diapause and post-diapause larvae, GA10647-PA unique in over-wintering diapause larvae, purple CG16784-PB isoform B and B0228.6 up-regulated in over-summering and overwintering diapause larvae. The potential functions of these proteins during wheat blossom midge diapause are discussed.
\end{abstract}

\section{INTRODUCTION}

Diapause is a genetically controlled period of developmental arrest that enables insects to survive adverse environmental conditions and synchronize their life cycles with the availability of food (Salama \& Miller, 1992; Li et al., 2008). Because of its central role in insect pest survival and reproduction, an understanding of the mechanism of diapause is important for agricultural pest management.

The molecular mechanisms of diapause have been studied extensively recently, and several proteins associated with diapause were found in some insect species. Salama \& Miller (1992) reported a 490 kDa glycolipoprotein in the hemolymph of last instar larva of the pink bollworm Pectinophora gossypiella during diapause. Other proteins, which have distinct expression patterns in relation to insect diapause, include a $41 \mathrm{kDa}$ protein in the larval fat body of the southwestern corn borer Diatraea grandiosella (Brown \& Chippendale, 1978), four proteins with molecular weights $30 \mathrm{kDa}, 35 \mathrm{kDa}, 55 \mathrm{kDa}$ and 60 $\mathrm{kDa}$ in the gut of pharate first instar larvae of the gypsy moth Lymantria dispar (Lee \& Denlinger, 1996), a 77 $\mathrm{kDa}$ protein (AgSP-1) in the haemolymph of the boll weevil Anthonomus grandis (Lewis et al., 2002) and a 23 $\mathrm{kDa}$ heat shock protein in the brain of diapausing pupae of the flesh fly Sarcophaga crassipalpis (Li et al., 2007).
The wheat blossom midge, Sitodiplosis mosellana (Gehin), is a serious intermittent pest damaging wheat in the northern hemi-sphere (Chen \& Ni, 1998; Ding \& Guo, 1992). Generally it has one generation per year. The mature larvae fall to the ground from middle to late May from wheat ears and form round cocoons in which the larvae over-summer and over-winter in obligatory diapause. Although diapause in the wheat blossom midge has been intensely investigated, most studies have focused on the ecology (Basedow, 1977; Hinks \& Doane, 1988) and the molecular control mechanism is unknown.

Proteomics is a large-scale study of gene expression at the protein level, which ultimately provides a direct measurement of protein expression levels and insight into the activity of relevant proteins. Recently, this approach was successfully used in studies of different aspects of entomology, such as induced immunity (Levy et al., 2004), resistance mechanisms (Jiang et al., 2004), molecular pathology (Kaeslin et al., 2005), developmental process (Li et al., 2006; Jia et al., 2007) and diapause (Joplin et al., 1990; Li et al., 2007). In this report, a proteomic approach was used to investigate the proteome of wheat blossom midge larvae in different stages of diapause in order to determine the relationship between protein expression and insect diapause. The results should facilitate further research into diapause regulation in the wheat blossom midge, which may lead to new ways of effectively controlling this insect pest.

\footnotetext{
* Corresponding author.
} 


\section{MATERIAL AND METHODS}

\section{Insect collection}

Wheat ears containing late instar larvae of the wheat blossom midge were harvested and put on soil in a field insectary in mid-May, 2006. Pre-diapause larvae were collected when the wheat was ripe in the experimental fields in mid-May, 2006. Over-summering and over-wintering larvae were collected in late July and late December, 2006, respectively. Post-diapause larvae were collected in mid-March, 2007. All larvae collected were stored at $-80^{\circ} \mathrm{C}$ until used.

\section{Main reagents}

Low molecular weight markers, SDS, acrylamide, bis-acrylamide, TEMED, Tris and PlusOne 2D Quant protein assay kit were purchased from Amersham Biosciences (Uppsala, Sweden). Trifluoroacetic acid, acetonitrile, iodacetamide and alpha-cyano-4-hydroxycinnamic acid were purchased from Sigma (St. Louis, MO). CHAPS, urea, dithiothreitol, immobilized $\mathrm{pH}$ gradient strip $13 \mathrm{~cm} \mathrm{pH} 3-10$, immobilized $\mathrm{pH}$ gradient buffer, ammonium persulphate and agarose were purchased from Sino-American Biotechnology (Luoyang, China). Mercaptoethanol, glycine, bromophenolblue, Coomassie Brilliant Blue R-250, methanol, $\mathrm{HCl}$, acetic acid and glycerol were obtained from Beijing Dingguo Biotechnology (Beijing, China).

\section{Preparation of protein sample}

One hundred larvae, previously stored at $-80^{\circ} \mathrm{C}$, were rinsed with double-distilled $\mathrm{H}_{2} \mathrm{O}$. Excess water was removed with the aid of filter paper. The larvae were then homogenized in $1.2 \mathrm{ml}$ ice cold $0.02 \mathrm{M}$ phosphate-buffered saline (PBS, pH 7.0) using a pre-chilled glass homogenizer. Insect debris was removed by centrifuging at $8,000 \times \mathrm{g}$ for $15 \mathrm{~min}$ at $4^{\circ} \mathrm{C}$, and the supernatant was then transferred into a $1.5 \mathrm{ml}$ centrifuge tube. After freezing overnight at $-80^{\circ} \mathrm{C}$, the supernatant was lyophilized in a FlexDry $^{\text {TM }}$ Lyophilizer (FTS Systems, Stone Ridge, NY). The lyophilized sample was rehydrated in a buffer containing $8 \mathrm{M}$ urea, $2 \%$ CHAPS, $0.5 \%$ IPG buffer and $1 \%$ DTT. Insoluble materials were removed by centrifugation. Protein concentration was determined using the PlusOne 2D Quant protein assay Kit following the procedure recommended by the manufacturer. At least three replicates were performed on each developmental stage.

\section{D gel electrophoresis}

First dimension gel electrophoresis was performed using an IPGphor isoelectric focusing (IEF) system (Amersham Biosciences, Uppsala, Sweden) by applying $200 \mu \mathrm{g}$ of protein extract in $250 \mu \mathrm{l}$ buffer to a $13 \mathrm{~cm}, \mathrm{pH} 3-10$ linear IPG strip with rehydration at $30 \mathrm{~V}$ for $12 \mathrm{~h}$ followed by isoelectric focusing at 500 $\mathrm{V}$ for $1 \mathrm{~h}, 1000 \mathrm{~V}$ for $1 \mathrm{~h}$ and $8000 \mathrm{~V}$ for $2 \mathrm{~h}$. After IEF separation, the strips were equilibrated for $15 \mathrm{~min}$ in an equilibration buffer $(50 \mathrm{mM}$ Tris- $\mathrm{HCl} \mathrm{pH} 8.8,6 \mathrm{M}$ urea, 30\% glycerol, $0.002 \%$ bromophenol blue, $2 \%$ SDS and $1 \%$ DTT). The strips were then treated for another $15 \mathrm{~min}$ with the same buffer, except $1 \%$ DTT was replaced with $2.5 \%$ iodacetamide. The equilibrated strips were subjected to a second-dimension electrophoresis after transferring onto a $15 \%$ SDS-polyacrylamide gel. Electrophoresis was run on the Hoefer SE 600 system (Amersham Biosciences, Uppsala, Sweden) at $10 \mathrm{~mA}$ per gel for $20 \mathrm{~min}$, followed by $20 \mathrm{~mA}$ until the bromophenol blue frontier reached the bottom of the gel. After separation, the gel was stained using colloidal Coomassie Brilliant Blue R-250.

\section{Image analysis}

Protein images on each gel were recorded using an ImageScanner (Amersham Biosciences, Uppsala, Sweden) and analyzed using PDQuest software release 7.4 (BioRad, Hercules, CA), including background subtraction, spot detection, spot matching and spot intensity normalization analysis (total density of gel image), following the protocols provided by the manufacturer.

\section{In-gel digestion and mass spectrometry}

Protein spots were excised from gels and subjected to in-gel digestion using trypsin following published procedures (Hellman et al., 1995; Courchesne \& Patterson, 1999) with slight modifications. Briefly, the gel pieces were destained with $50 \mathrm{mM}$ ammonium bicarbonate, $50 \%$ and $100 \%$ acetonitrile and then treated with $10 \mathrm{mM}$ dithiothreitol (in $25 \mathrm{mM}$ ammonium bicarbonate) and $55 \mathrm{mM}$ iodacetamide (in $25 \mathrm{mM}$ ammonium bicarbonate) to reduce and alkylate the cysteines. After that, the gel pieces were washed with $25 \mathrm{mM}$ ammonium bicarbonate in $50 \%$ acetonitrile, dehydrated with $100 \%$ acetonitrile and dried in a vacuum centrifuge. The gel pieces were then rehydrated in $25 \mathrm{mM}$ ammonium bicarbonate containing trypsin and digestion carried out overnight at $37^{\circ} \mathrm{C}$. The enzymatic reactions were stopped by the addition of $2 \%$ trifluoroacetic acid. After centrifugation, the peptide mixture was transferred into a clean 0.5 $\mathrm{ml}$ centrifuge tube and then concentrated in a SpeedVac (Savant) to $10 \mu 1.0 .5 \mu 1$ of the concentrated mixture was mixed again with $0.5 \mu 1$ of saturated $\alpha$-cyano-4-hydroxycinnamic acid matrix solution, applied to a stainless steel target MALDI plate and air-dried before analysis in a mass spectrometer.

Mass spectrometry was performed on a MALDI-TOF spectrometer (Bruker Autoflex) equipped with a nitrogen laser (337 $\mathrm{nm})$. Peptide mass fingerprint spectra were obtained in the reflectron positive mode by summing 200 laser shots with delayed extraction $(90 \mathrm{~ns})$, an accelerated ion source voltage 1 of $19.1 \mathrm{kV}$ and accelerated ion source voltage 2 of $16.4 \mathrm{kV}$, calibrated using matrix and trypsin autolysis peaks (at $\mathrm{m} / \mathrm{z}$ 842.51 and 2211.11) as internal standards.

\section{Protein identification}

Proteins were identified using peptide mass fingerprinting (PMF) performed by Mascot on-line search engine (http: //www.matrixscience.com) and reference to the National Center for Biotechnology non-redundant (NCBInr) protein database. The search parameters used were enzyme of trypsin; monoisotopic masses; fixed modifications of carbamidomethyl (C); variable modifications of Gln->pyro-Glu (N-term Q), oxidation (M); peptide charge state of $1+$; peptide mass tolerance of \pm 100 ppm and one max missed cleavages. Only significant hits, defined by mascot probability analysis $(P<0.05)$, were accepted.

\section{RESULTS}

\section{2-DE analyses of extracts of larvae in different stages of diapause}

Analysis of the three replicates of each sample produced consistent results. Representative images of 2-DE gels of the protein extracts from larvae in different stages of diapause are shown in Fig. 1. The analysis done by PDQuest software indicated that about 300 protein spots were repeatedly detected in the extracts of pre-diapause larvae and 275 in each of those of other diapause stages in the molecular weight range from approximately 7.0-94.0 $\mathrm{kDa}$ and isoelectric points range from about $3.0-10.0$, and that the majority of the proteins had 

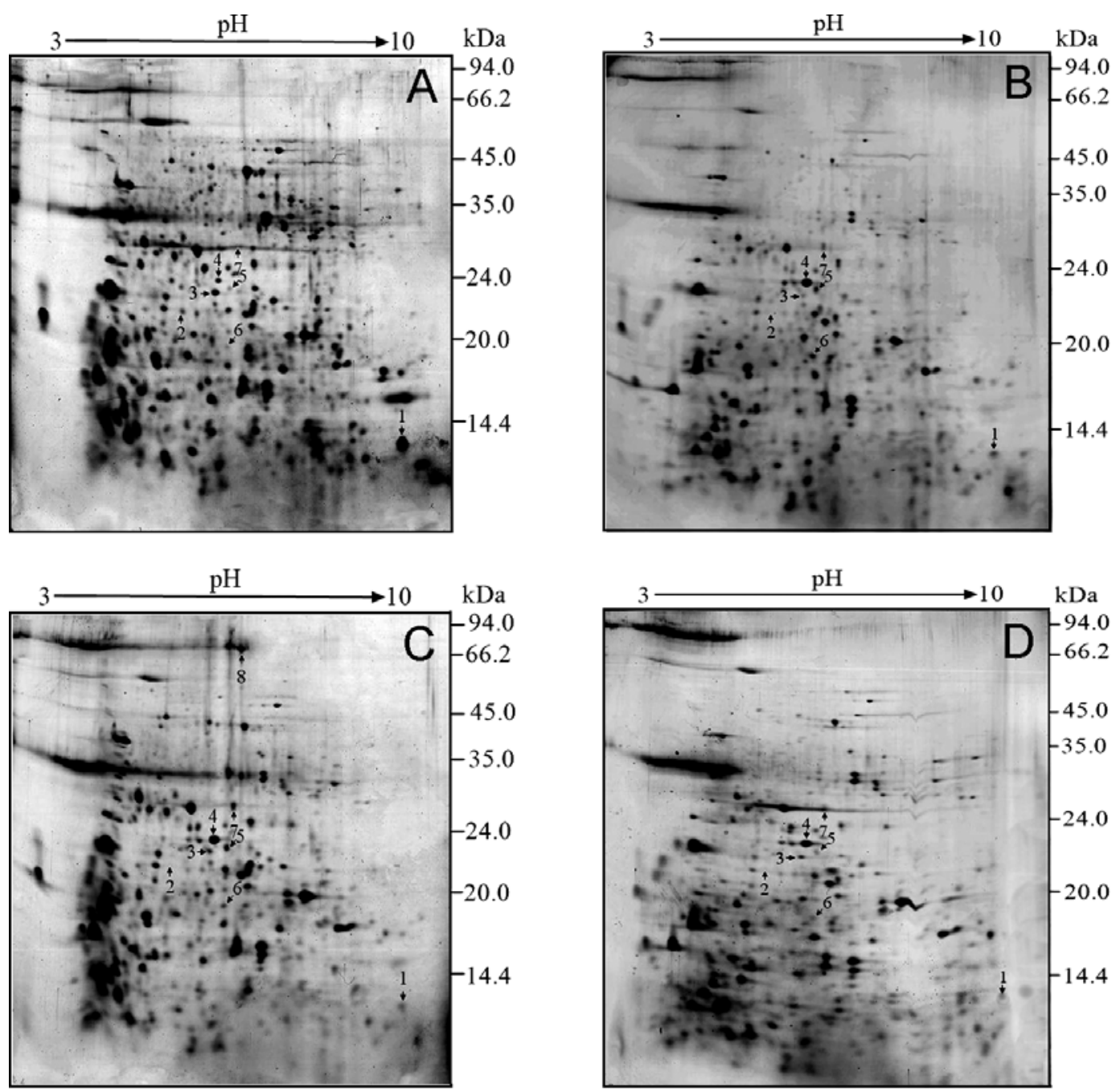

Fig. 1. Two-dimensional electrophoresis maps of proteins from (A) pre-diapause, (B) over-summering diapause, (C) overwintering diapause and (D) post-diapause larvae of S.mosellana. Proteins were separated by IEF in the first dimension, $\mathrm{pH}$ 3-10, 13 $\mathrm{cm}$, then by molecular weights (14.4-94 kDa) in the second dimension and stained with Coomassie Brilliant Blue. Maps were analyzed using PDQuest software. Selected spots are numbered 1-8.

molecular weights ranging from $8.0-50.0 \mathrm{kDa}$ and isoelectric points from about 4.0-9.0.

\section{Differential expression of proteins among larvae in different stages of diapause}

A comparison of the location and volume of each spot revealed that the majority of proteins were expressed at similar levels in all the larvae. However, there was a distinct portion of proteins that were expressed differentially with at least a two-fold difference among larvae in different stages of diapause. Specifically, 91 proteins differed in abundance in the extracts of larvae in over-summering diapause compared to those in pre-

TABLE 1. The relative level of expression of eight proteins in larvae at different stages of diapause.

\begin{tabular}{ccccc}
\hline \multirow{2}{*}{ Protein no. } & \multicolumn{5}{c}{ Diapause stage } \\
\cline { 2 - 5 } & Pre-diapause & Over-summering diapause & Over-wintering diapause & Post-diapause \\
\hline 1 & 1 & 0.33 & 0.23 & 0.04 \\
2 & + & - & - & - \\
3 & 1 & 0.22 & 0.47 & 0.43 \\
4 & 1 & 6.33 & 2.89 & 3.05 \\
5 & 1 & 4.35 & 4.26 & $\approx$ \\
6 & 1 & 3.96 & 3.39 & $\approx$ \\
7 & - & + & + & + \\
8 & - & - & + & - \\
\hline
\end{tabular}

Note: - missing protein, + unique protein, $\approx$ change in protein abundance was less than twice that in pre-diapause larvae. The data in columns $3-5$ of this table were the rates of protein abundance in other stages to that in pre-diapausing stage. 


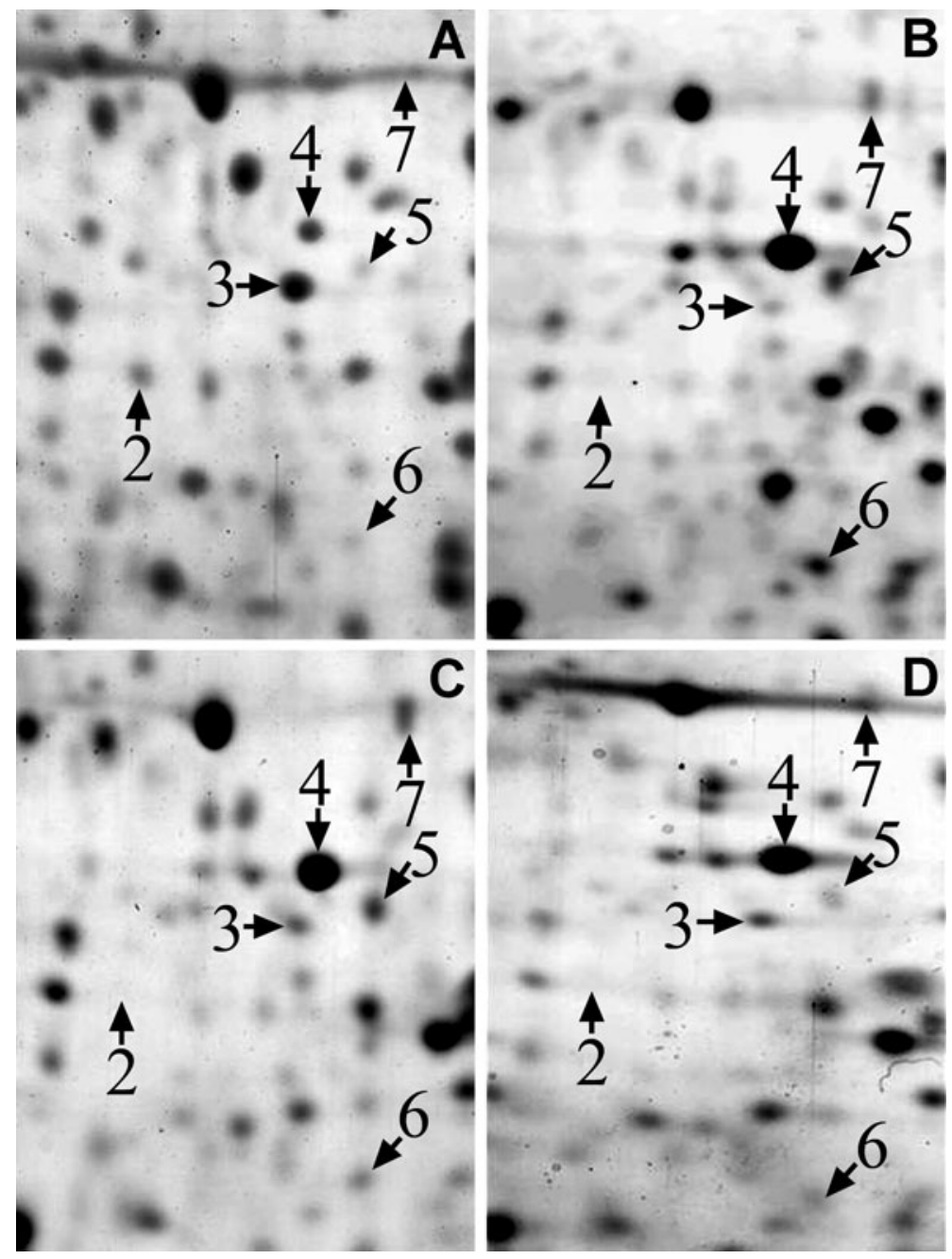

Fig. 2. Enlarged images of the areas of the maps in Fig. 1 that contain six of the eight selected proteins in the extracts of (A) prediapause, (B) over-summering diapause, (C) over-wintering diapause and (D) post-diapause larvae of S. mosellana.

diapause. Of these 91 proteins, 26 were unique or upregulated during over-summering diapause, while 65 were either missing or downregulated. During over-wintering diapause, 92 proteins exhibited different expression levels compared to pre-diapause. Of these 92 proteins, 39 were unique or upregulated whereas 53 were either missing or downregulated in over-wintering larvae compared to prediapause. Similarly, the expression levels of 95 proteins differed at post-diapause compared to pre-diapause. Of these 95 proteins, 22 were unique or upregulated, whereas 73 were either missing or downregulated in post-diapause larvae compared to pre-diapause larvae.

Overall, the differences in levels of protein expression were smaller among larvae in over-summering diapause, over-wintering diapause and post-diapause than between the levels in them and the level in pre-diapause larvae. The main differences between the level in pre-diapause larvae and other larvae were the low abundance of unique proteins in pre-diapause larvae. Molecular weights of these proteins were approximately $28.0-40.0 \mathrm{kDa}$, with isoelectric points of $6.6-9.3$ and $30.0-46.0 \mathrm{kDa}$, with isoelectric points of 4.2-6.4.
Among the differentially expressed proteins, eight were selected for MALDI-TOF-MS analysis because of their consistent differences among pre-diapause, diapause and post-diapause larvae (Table 1). Protein 1 and 3 were significantly downregulated during both over-summering and over-wintering diapause as well as post-diapause. Protein 2 was expressed during pre-diapause, but absent during diapause and post-diapause. Protein 4 and 7 were dramatically upregulated during diapause and postdiapause. Protein 5 and 6 were upregulated during oversummering and over-wintering, but not significantly so in post-diapause larvae. Protein 8 was unique to larvae in over-wintering diapause. These eight protein spots are indicated in Fig. 1A, B, C and D, and six of them at a great magnification in Fig. 2.

\section{MALDI-TOF-MS analysis and protein identification}

The eight spots selected were excised from the gels and subjected to in-gel digestion with trypsin and MALDITOF-MS analysis. Fig. 3 shows the separation profile of protein 5 . All other proteins yielded satisfactory peptide mass fingerprints (PMF).

The PMF data for individual proteins were used to search the NCBInr database using the Mascot search 


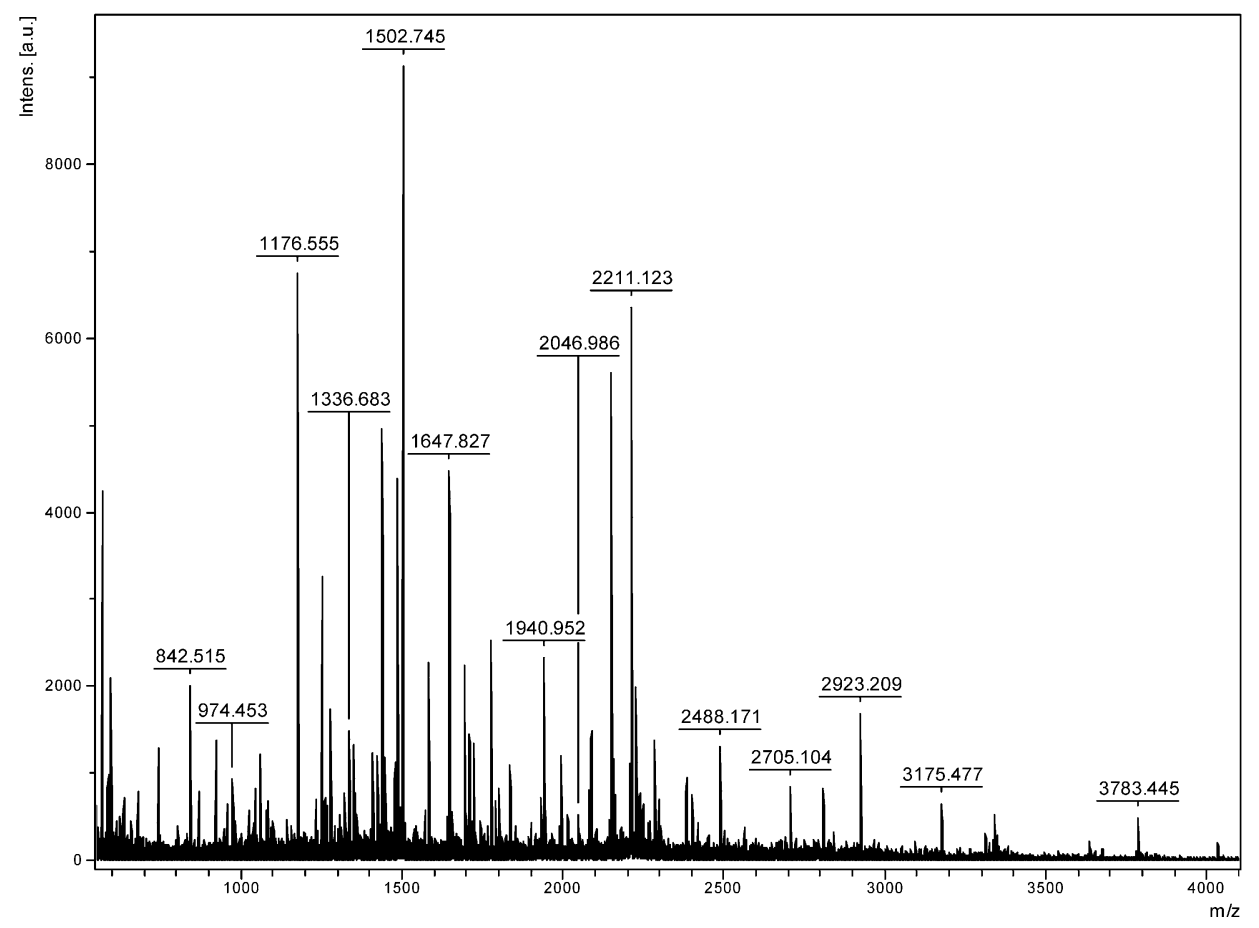

Fig. 3. Peptide mass fingerprint of protein 5.

engine. Seven of the eight proteins were successfully identified with $P<0.05$. They were proopiomelanocortin for protein 1, F10F2.5 for protein 2, NADH dehydrogenase subunit 1 for protein 3 , IKK interacting protein isoform 2 for protein 4, purple CG16784-PB isoform B for protein 5, B0228.6 2 for protein 6 and GA10647-PA for protein 8 , respectively. Protein 7 was not identified and is possibly a novel protein. The NCBI accession numbers, sequence coverage of peptides, Mowse scores, and theoretical molecular weights and pIs for these proteins are shown in Table 2.

\section{DISCUSSION}

The complete genome sequencing of many organisms and new advances in proteomics make it possible to analyze global differences in protein among organisms or of the same organism at different developmental stages or experiencing different environmental conditions. Insect diapause, a biological process that allows insects to survive adverse conditions, involves extensive physiological changes (Joanisse \& Storey, 1994; Li et al., 2002), and potentially proteins are either upregulated or downregulated during the different stages of diapause. Indeed, preliminary analysis using SDS-PAGE has detected qualitative and quantitative differences during diapause in several insects (Osir et al., 1989; Ichimor et al., 1990; Mao \& Cao, 2001). However, very few proteins that may play a role in insect diapause have been identified. In this study, protein expression profiles of the wheat blossom midge larvae during pre-diapause, over-summering diapause, over-wintering diapause and post-diapause were compared. About 300 protein spots were detected in extracts of pre-diapause larvae and 275 protein spots in those in other stages. Of these protein spots, 91, 92 and 95 were more than twice as abundant in larvae in oversummering diapause, over-wintering diapause and postdiapause compared to pre-diapause. The general trend was that the majority of these differentially expressed proteins, for example, proteins 53 and 65, were downregulated or absent during diapause. Only a couple of

TABLE 2. Proteins identified by PMF.

\begin{tabular}{|c|c|c|c|c|c|c|}
\hline $\begin{array}{c}\text { Protein } \\
\text { no. }\end{array}$ & NCBI GI & Homologous protein name & Species & $\begin{array}{c}\text { Sequence } \\
\text { coverage (\%) }\end{array}$ & $\begin{array}{l}\text { Mowse } \\
\text { score }\end{array}$ & $\begin{array}{c}\text { Theoretical } \\
\mathrm{Mr}(\mathrm{kDa}) / \mathrm{pI}\end{array}$ \\
\hline 1 & 213469 & Proopiomelanocortin & Oncorhynchus keta & 65 & 87 & $11.70 / 9.93$ \\
\hline 2 & 71984420 & F10F2.5 & Caenorhabditis elegans & 28 & 60 & $61.22 / 5.78$ \\
\hline 3 & 3021562 & NADH dehydrogenase subunit 1 & Pinus sylvestris & 100 & 85 & $4.89 / 9.21$ \\
\hline 4 & 42491362 & IKK interacting protein isoform 2 & Homo sapiens & 28 & 84 & $39.40 / 9.21$ \\
\hline 5 & 19550074 & purple CG16784-PB, isoform B & Drosophila melanogaster & 53 & 88 & $19.50 / 6.71$ \\
\hline 6 & 25150027 & B0228.6 & Caenorhabditis elegans & 50 & 74 & $17.50 / 6.15$ \\
\hline 7 & - & Unknown & - & - & - & - \\
\hline 8 & 125808983 & GA10647-PA & Drosophila pseudoobscura & 25 & 61 & $69.68 / 8.38$ \\
\hline
\end{tabular}


proteins, i.e. proteins 26 and 39, were upregulated or unique to over-summering and over-wintering diapause larvae, respectively. This result is consistent with the fact that the metabolism of insects is low during diapause, resulting in a lower synthesis of proteins. Whereas some chemicals that are necessary for diapause survival, such as glycerol, trehalose and antifreeze proteins, increase during diapause. Thus the levels of the enzymes necessary for the synthesis of these compounds increase (Joanisse \& Storey, 1994; Li et al., 2000). Identification of these differentially expressed proteins and elucidation of the regulatory mechanism will advance our understanding of their role in insect diapause.

Through MALDI-TOF-MS analysis, we have for the first time identified seven proteins that were either up- or downregulated during the different diapause stages. Among the seven proteins, four were dramatically upregulated or uniquely expressed during diapause (Tables 1, 2). These upregulated or unique proteins include IKK interacting protein isoform 2 (IKIP2), GA10647-PA, purple CG16784-PB isoform B and B0228.6. The IKK interacting protein can promote apoptosis and inhibit cell division (Hofer-Warbinek et al., 2004). Since insect diapause is a dormant stage during which it is likely cell division is inhibited, the strong upregulation of IKIP2 during diapause may suggest a role of this protein in inhibiting cell division during diapause. Therefore, we speculate that this protein may play a regulatory role in diapause activation of wheat blossom midge larvae. GA10647-PA functions like phosphoenolpyruvate carboxykinase, which is a critical enzyme in gluconeogenesis (Richards et al., 2005). This protein is necessary for the production of phosphoenolpyruvate and glyceraldehyde-3-phosphate, which are precursors of the cryoprotectant glycerol. The fact that this protein was uniquely expressed during over-wintering suggests that it may be involved in cold tolerance of wheat blossom midge by reducing the supercooling point. CG16784-PB isoform B is highly homologous with 6-pyruvoyl tetrahydropterin synthase, which is involved in the biosynthesis of pteridine and tetrahydrobiopterin. The function of B0228.6 is unclear. Both CG16784-PB and B0228.6 were highly upregulated during both over-summering and over-wintering, and their roles in diapause remain to be resolved.

In contrast to the four proteins that were upregulated during diapause, three proteins, including F10F2.5, proopiomelanocortin and NADH dehydrogenase subunit 1, were strongly downregulated during diapause. F10F2.5 is a protein involved in increasing growth rate. This protein is not expressed during diapause. This observation is consistent with the fact that insect development is suppressed transiently during diapause. Proopiomelanocortin is the precursor of a number of biologically active peptides in the pituitary of animals, and its expression is regulated by several signal regulatory molecules in the cytoplasm and nucleus (Seo et al., 2008). Our results showed that this protein was markedly less abundant during and after diapause, suggesting that this protein may be connected with diapause related signal transduction. NADH dehydrogenase is a key metabolic enzyme in the mitochondrion respiratory chain. The downregulation of this enzyme may reflect the fact that metabolism is less active during diapause. Diapause is characterized by a major shut-down of metabolism and it is not surprising that the proteins associated with metabolic activities were less abundant during diapause. The downregulation of metabolic enzymes was also recorded in the flesh fly Sarcophaga crassipalpis (Li et al., 2007). Several proteins involved in primary metabolism, including a fatty acid binding protein and an endonuclease, were downregulated in diapausing pupae. Proteins that are less abundant in diapausing larvae could potentially be just as important as proteins that are unique to diapause or are more abundant during diapause. At the transcript level, for example, down-regulation of the cell cycle regulator, Proliferating Cell Nuclear Antigent, appears to be a key feature in shutting down the cell cycle during diapause in the flesh fly (Hayward et al., 2005).

In summary, we used a proteomic approach to analyze global differences in protein in the larvae of the wheat blossom midge in different stages of diapause. Numerous proteins that were differentially expressed in the different diapause stages were identified. With the aid of MALDITOF-MS analysis, a further seven proteins that were either up or downregulated during diapause were identified. These results should facilitate further analysis with the objective of revealing the molecular mechanism that regulates the diapause process in the wheat blossom midge.

ACKNOWLEDGMENTS. This research was supported by grants from The Ministry of Education of China (105165), the National Science Foundation of China (30370936) and the Research Program of Science and Technology in the Eleventh Five-year Plan of China (2006BAD08A05). We deeply thank J.-Z. Liu of Hebei Normal Uiversity, China for his technical assistance; M.-S. Chen in the Plant Science and Entomology Research Unit, USDA-ARS and Department of Entomology, Kansas State University, USA and H. Chen, H.-X. Zhao from Northwest A \& F University, China for their suggestions and comments

\section{REFERENCES}

BAsEdow T. 1977: The effect of temperature and precipitation on diapause and phenology in the wheat blossom midges Contarinia tritici (Kirby) and Sitodiplosis mosellana (Gehin) (Diptera: Cecidomyiidae). Zool. Jb. Abt. System. Okol. Geogr. Tiere 104: 302-326.

Brown J.J. \& Chippendale G.M. 1978: Juvenile hormone and a protein associated with the larval diapause of the southwestern corn borer, Diatraea grandiosella. Insect Biochem. 8: 359-367.

Chen J.L. \& Ni H.X. 1998: Research advance on wheat midge. Entomol. Knowl. 35: 240-243.

Courchesne P.L. \& Patterson S.D. 1999: Identification of proteins by matrix-assisted laser desorption/ionization mass spectrometry using peptide and fragment ion masses. Methods Mol. Biol. 112: 487-511.

Ding H.J. \& GuO Y.Y. 1992: Research dynamic on wheat midge. Agric. World 5: 31-32. 
Hayward S.A.L., Pavlides S.C., Tammariello S.P., Rinehart J.P. \& DENLINGER D.L. 2005: Temporal expression patterns of diapause associated genes in flesh fly pupae from the onset of diapause through post-diapause quiescence. J. Insect Physiol. 51: 631-640.

Hellman U., Wernstedt C., Conez J. \& Heldin C.H. 1995: Improvement of an "In-Gel" digestion procedure for the micropreparation of internal protein fragments for amino acid sequencing. Analyt. Biochem. 224: 451-455.

Hinks C.F. \& DoAne J.F. 1988: Observations on rearing and diapause termination of Sitodiplosis mosellana (Diptera: Cecidomyiidae) in the laboratory. J. Economol. Entomol. 81: $1816-1818$.

Hofer-Warbinek R., Schmid J.A., Mayer H., Winsauer G., Orel L., Mueller B., Wiesner C., Binder B.R. \& de Martin R. 2004: A highly conserved proapoptotic gene, IKIP, located next to the APAF1 gene locus, is regulated by p53. Cell Death Differ. 11: 1317-1325.

Ichimori T., Ohtomo R., Suzuki K. \& Kurihara M. 1990: Specific protein related to adult diapause in the leaf beetle, Gasteophysa atrocyanea. J. Insect Physiol. 36: 85-91.

Jia S.H., Li M.W., Zhou B., LiU W.B., Zhang Y., Miao X.X., Zeng R. \& HuANG Y.P. 2007: Proteomic analysis of silk gland programmed cell death during metamorphosis of the silkworm Bombyx mori. J. Proteome Res. 6: 3003-3010.

Jiang C.F., LiU K.Y. \& Peng R. 2004: Differential proteomic analysis of Bt Cry1Ac toxin-resistant and susceptible BTI-Tn5B1-4 cells. Acta Entomol. Sin. 47: 686-690.

JoAnisse D.R. \& Storey K.B. 1994: Enzyme activity profiles in an overwintering population of freeze-tolerant larvae of the gall fly, Eurosta solidaginis. J. Compar. Physiol. (B) 164: 247-255.

Joplin K.H., Yocum G.D. \& Denlinger D.L. 1990: Diapause specific protein expreseed by the brain during the pupal diapause of the flesh fly, Sarcophaga crassipalpis. J. Insect Physiol. 36: 775-783.

Kaeslin M., Pfister-Wilhelm R., Molina D. \& Lanzrein B. 2005: Changes in the haemolymph proteome of Spodoptera littoralis induced by the parasitoid Chelonus inanitus or its polydnavirus and physiological implication. J. Insect Physiol. 51: $975-988$.

LeE K.Y. \& Denlinger D.L. 1996: Diapause-regulated proteins in the gut of pharate first instar larvae of the gypsy moth, Lymantria dispar, and the effect of KK-42 and neck ligation on expression. J. Insect Physiol. 42: 423-431.

Levy F., Bulet P. \& Ehret-Sabatier L. 2004: Proteomic analysis of the systemic immune response of Drosophila. Mol. Cell. Proteom. 3: 156-166.

Lewis D.K., Spurgeon D., Sappington T.W. \& Keeley L.L. 2002: A hexamerin protein, AgSP-1, is associated with diapause in the boll weevil. J. Insect Physiol. 48: 887-901.
Li A.Q., Popova-Butler A., Dean D.H. \& Denlinger D.L. 2007: Proteomics of the flesh fly brain reveals an abundance of upregulated heat shock proteins during pupal diapause. $J$. Insect Physiol. 53: 385-391.

Li W.X., Li J.C., Lu Z.Y., Liu X.X. \& Zhang Q.W. 2008: Critical photoperiod and sensitive stage of diapause induction in Microplitis mediator (Haliday) (Hymenoptera: Braconidae). Acta Entomol. Sin. 51: 635-639.

Li X.H., Wu X.F., Yue W.F., Liu J.M., Li G.L. \& MiaoY.G. 2006: Proteomic analysis of the silkworm (Bombyx mori L.) hemolymph during developmental stage. J. Proteom. Res. 5: 2809-2814.

Li Y.P., Gong H. \& PARK H.Y. 2000: Profile of enzymic activity in overwintering mature larvae of the pine needle gall midge, Thecodiplosis japonensis. Acta Entomol. Sin. 43: 227-232.

Li Y.P., OGuchi S. \& Goto M. 2002: Physiology of diapause and cold hardiness in overwintering pupae of the apple leaf miner Phyllonorycter ringoniella in Japan. Physiol. Entomol. 27: 92-96.

MAO W.F. \& CAO M.X. 2001: Isolation and purification of diapause-associated proteins from hemolymph in Ostrinia furnacalis. Acta Entomol. Sin. 44: 389-394.

Osir E.O., Labongo L.V. \& Unntithan G.C. 1989: A high molecular weight diapause associated protein from the stem borer, Busseola fusca, purification and properties. Arch. Insect Biochem. Physiol. 11: 173-187.

Richards S., Liu Y., Bettencourt B.R., Hradecky P., Letovsky S., Nielsen R., Thornton K., Hubisz M.J., Chen R., Meisel R.P., Couronne O., Hua S., Smith M.A., Zhang P., Liu J., Bussemaker H.J., van Batenburg M.F., Howells S.L., Scherer S.E., Sodergren E., Matthews B.B., Crosby M.A., Schroeder A.J., Ortiz-Barrientos D., Rives C.M., Metzker M.L., Muzny D.M., Scott G., Steffen D., Wheeler D.A., Worley K.C., Havlak P., Durbin K.J., Egan A., Gill R., Hume J., Morgan M.B., Miner G., Hamilton C., HuangY., Waldron L., Verduzco D., Clerc-Blankenburg K.P., DubChak I., Noor M.A., Anderson W., White K.P., Clark A.G, Schaeffer S.W., Gelbart W., Weinstock G.M. \& Gibbs R.A. 2005: Comparative genome sequencing of Drosophila pseudoobscura: chromosomal, gene, and cis-element evolution. Genome Res. 15: 1-18.

Salama M.S. \& Miller T.A. 1992: A diapause associated protein of the pink bollworm Pectinophora gossypiella Saunder. Arch. Insect Biochem. Physiol. 21: 1-11.

Seo Y.J., Kwon M.S., Chol S.S., Han E.J., Jung J.S., Chol H.W., PARK S.H., JANG J.E. \& SUH H.W. 2008: Characterization of the hypothalamic proopiomelanocortin gene and $\alpha$-endorphin expression in the hypothalamic arcuate nucleus of mice elicited by inflammatory pain. Neuroscience 152: 1054-1066.

Received August 19, 2008; revised and accepted November 13, 2008 